\title{
Comentario a la supresión de los Gobernadores Civiles por la Ley de Organización y Funcionamiento de la Administración General del Estado (LOFAGE)
}

\author{
Isabel Melús Gil \\ Profesora Asociada de Derecho Constitucional \\ Escuela Universitaria de Estudios Empresariales de Huesca
}

Sumario: I. INTRODUCCIÓN. II. ANTECEDENTES HISTÓRICOS. III. GOBERNADORES CIVILES: ¿SUPRESIÓN REAL O CAMBIO DE DENOMINACION?

\section{INTRODUCCIÓN}

El 14 de abril de 1997 es aprobada la Ley de Organización y Funcionamiento de la Administración General del Estado ', a partir de ahora LOFAGE. Esta Ley nace con un objetivo básico como es la necesaria reordenación de la estructura administrativa, en función de la realidad social, compaginando los criterios de eficacia, racionalidad y de economía del gasto público que se consiguen evitando la duplicidad de la gestión de servicios.

\section{La LOFAGE pretende varias cosas:}

* Estructurar la Administración del Estado para que exista un mayor contacto con el ciudadano. La Administración al servicio del ciudadano y no viceversa.

* Aplicar el lema de «austeridad económica» que tanto predican los dirigentes políticos, para conseguir un menor gasto público y una reducción de la planta administrativa, eso sí, sin perder eficacia en la gestión de los servicios que se prestan al ciudadano. Porque de que servirá una reducción del gasto si se produce una deficiente gestión de los servicios que obliga al ciudadano a acudir al sector privado. Se debe conseguir compaginar el menor gasto posible con una eficaz calidad de servicios.

1 Ley 6/1997, de 14 de abril, de Organización y Funcionamiento de la Administración del Estado (LOFAGE) publicada en el BOE de 15 de abril de 1997. 
* Regular la Administración General del Estado en el exterior y las figuras de embajadores y representantes permanentes.

* Racionalizar la Administración Institucional del Estado, optando para ello por una denominación más genérica, que engloba a todas las Entidades de Derecho Público dependientes o vinculadas a la Administración General del Estado, como son los «Organismos Públicos».

* Una profesionalización de la Administración General del Estado. Se pretende que los órganos directivos estén ocupados por personal al servicio de la Administración, concretamente, de funcionarios a los que se les exija titulación superior.

* Una reestructuración de la Administración Periférica del Estado, acorde con el modelo de Estado autonómico que representa nuestro país, desde la entrada en vigor de nuestra actual Carta Magna.

Con relación a este último punto, señalar que el 5 de mayo de 1997 y como consecuencia de la entrada en vigor del Real Decreto 617/1997, de 25 de abril ${ }^{2}$, dictado al amparo del Título II, Capítulo II, Sección 2. ${ }^{a}$ de la LOFAGE, ha desaparecido de la esfera política y administrativa española una figura carismática que vio la luz en la Constitución gaditana, que recibió distintos apelativos a lo largo de nuestra azarosa historia constitucional, hasta que en 1849 se consagró definitivamente con la denominación que ha perdurado hasta nuestros días, me refiero, a los Gobernadores Civiles.

El Gobernador Civil era una figura que jugó un papel destacado en la época franquista donde eran los representantes del Estado en la provincia con fuertes competencias en orden de seguridad y que vio como su existencia se ponía en duda con la instauración a partir de los años 80 del denominado Estado de las Autonomías y la aparición de los Delegados del Gobierno.

Con la entrada en vigor de la LOFAGE y el Decreto 617/1997 se soluciona esa posible duplicidad de figuras haciendo desaparecer a una y potenciando la otra. Ahora el máximo representante de la Administración Periférica va a ser el Delegado del Gobierno que ejercerá la dirección y supervisión de todos los servicios de la Administración General del Estado y de sus Organismos públicos en el ámbito de la Comunidad Autónoma. Además, los Delegados tienen la competencia de nombrar a los Subdelegados del Gobierno en la provincia y dirigir y coordinar como superior jerárquico la actividad de aquéllos. En definiti-

2 Real Decreto 617/1997, de 25 de abril, de Subdelegados del Gobierno y Directores Insulares de la Administración General del Estado. Publicado en el BOE de 3 de mayo de 1997. 
COMENTARIO A LA SUPRESIÓN DE LOS GOBERNADORES CIVILES ...

va, la LOFAGE establece de manera clara la superioridad de los Delegados del Gobierno.

\section{ANTECEDENTES HISTÓRICOS ${ }^{3}$}

La figura del Gobernador Civil respondía a principios de organización administrativa y su origen se sitúa en el siglo XIX, aunque no podemos olvidar que en la época visigótica los duques y condes realizaban funciones similares, posteriormente, los adelantados y merinos, los corregidores de la Reconquista, los asistentes de los Reyes Católicos, los intendentes de Felipe V y los intendentes-corregidores de Fernando VI. Pero su configuración moderna se inicia con la Constitución de 1812 cuando se produce la separación de las funciones judiciales de las administrativas.

En 1812, se intenta llevar a cabo una organización racional del territorio y para ello, se divide éste en provincias al frente de las cuales se establece un Jefe Político. Éste será representante e interventor del poder central en la provincia, además del nexo de unión entre municipios y provincias. Por tanto, se convierte en una figura nombrada por el Rey que actuará como delegado del Gobierno en la periferia donde realizará tareas de interés general y tendrá encomendada la suprema dirección de las funciones administrativas.

Unos años más tarde, y por Real Decreto de 23 de octubre de 1833 y tras la aparición del Ministerio de Fomento, ve la luz una figura que, desde el punto de vista terminológico, se asemeja a la que nace en mayo de 1997, me refiero a los Subdelegados de Fomento que será la autoridad superior de la provincia que deberá proteger los intereses y trabajar por la prosperidad de ésta; eso sí, se diferencia de los Jefes Políticos de 1812 y de los desaparecidos Gobernadores Civiles, en que estos Subdelegados de Fomento no tenían a su cargo el mantenimiento del Orden Público. Al año siguiente, y tras un cambio de denominación del Ministerio, éstos pasan a denominarse por Real Decreto de 13 de mayo de 1834, Gobernadores civiles. Diez años más tarde, vuelve a reaparecer en la vida española la figura del Jefe Político y no será hasta el Decreto de 28 de diciembre de 1849, cuando al suprimirse el Jefe Político y el Intendente, se hable definitivamente de Gobernador Civil como autoridad superior en cada provincia.

3 J. Sánchez-Arcilla Bernal, Historia de las Instituciones Político-Administrativas Contemporáneas (1808-1975). Dykinson, 1994.

M. Santana Molina, La Diputación Provincial en la España decimonónica. Colección Historia de la Administración. Ministerio para las Administraciones Públicas, Madrid, 1989.

M. Baena del Alcázar, Curso de Ciencia de la Administración. Ed. Tecnos, Madrid, 1990. 
En 1849 comienza la evolución y desarrollo de una pieza clave en la función de gobierno interior que tras reconocerse constitucionalmente a la provincia como división territorial para el cumplimiento de los fines del Estado, se hicieron imprescindibles como representantes permanentes del Gobierno de la nación en la provincia y eje de todos los servicios civiles periféricos en el territorio de su jurisdicción. Ya en el Estatuto Provincial de 1925 se les atribuyen todas las facultades que el Gobierno les encomendara dentro de la provincia y es, en este momento, cuando el Gobernador pasa de ser un órgano de la provincia a ser un órgano del Estado en la provincia, un mero delegado del gobierno. Con el Decreto de 10 de octubre de 1958 se amplían las competencias de éstos. Con la entrada en vigor de la Constitución de 1978 y la creación de un Estado autonómico, esta figura es regulada en el Real Decreto 3117/1980, de 27 de diciembre, del Estatuto de los Gobernadores Civiles, que ha estado vigente hasta mayo de 1997.

Los Gobernadores Civiles han sido ${ }^{4}$, según el profesor ARENILLA, «el auténtico representante del Gobierno en su territorio, la provincia, mientras sea esa demarcación dominante política y administrativa a efectos de organización».

\section{GOBERNADORES CIVILES: ¿SUPRESIÓN REAL O CAMBIO DE DENOMINACIÓN?}

El Gobernador Civil era la primera autoridad estatal en la provincia, el representante permanente del Gobierno de la nación en ella, así como un órgano periférico del Ministerio del Interior. Responsable y ejecutor de la política del Gobierno central en la provincia. Con su desaparición en mayo de 1997, ¿quién va asumir esta función?, ¿se va a dejar al Delegado del Gobierno como único representante y responsable del Gobierno Central en las CC.AA.? Como no podía ser de otra manera en nuestro país, la desaparición de esta figura conlleva el nacimiento de otra, como es la del Subdelegado del Gobierno en la provincia. De ahí, que me plantee los siguientes interrogantes:

* ¿Se ha suprimido un órgano o simplemente se ha producido un cambio de denominación?

* ¿Esta supresión es el comienzo de una verdadera remodelación de la Administración Pública con el recorte de cargos públicos y el inicio de una auténtica y progresiva profesionalización de ésta?

4 M. ARenilla, Modernización de la Administración Periférica, MAP, Madrid, 1991. 
COMENTARIO A LA SUPRESIÓN DE LOS GOBERNADORES CIVILES ...

* ¿Se trasladan todas las competencias atribuidas al Gobernador Civil al Delegado del Gobierno o van a ser ejercidas por estos nuevos Subdelegados?

Y lo que una amplia mayoría nos preguntamos: ¿ha sido esta supresión de los Gobernadores Civiles el fruto de un compromiso político o es verdaderamente el inicio de una remodelación de la Administración que conllevará en un futuro no muy lejano a una supresión de las tan discutidas «Diputaciones Provinciales»? El tiempo nos dará la solución.

Una vez planteados estos interrogantes, expondré las diferencias entre Gobernadores Civiles y Subdelegados del Gobierno atendiendo a sus normas reguladoras:

* Los Subdelegados son nombrados por Resolución del Delegado del Gobierno, mientras que los Gobernadores Civiles eran altos cargos de la Administración nombrados por Decreto del Gobierno, a propuesta del Ministerio del Interior.

* Los Gobernadores Civiles dependían orgánica y funcionalmente del Ministerio del Interior, mientras los Subdelegados dependen jerárquicamente del Delegado del Gobierno que ha sido nombrado por Real Decreto del Consejo de Ministros y que dependen de la Presidencia del Gobierno y orgánicamente del Ministerio de Administraciones Públicas.

* Los Gobernadores Civiles eran representantes directos del Gobierno Central, mientras los Subdelegados del Gobierno son simples funcionarios.

* Según el art. 4, RD 3117/1980, de 27 de diciembre, del Estatuto de los Gobernadores Civiles, para ser nombrados se requería: ser español, mayor de 25 años y estar en el pleno uso de los derechos civiles y políticos. Ahora, según la LOFAGE y el RD 617/1997, de 25 de abril, siguiendo el principio de profesionalización de la Administración para conseguir garantizar la objetividad en el servicio a los intereses generales, los Subdelegados del Gobierno se nombrarán por el sistema de libre designación entre funcionarios de carrera del Estado, de las Comunidades Autónomas o de las Entidades Locales, a los que se exija para su ingreso el título de Doctor, Licenciado, Ingeniero, Arquitecto o equivalente. En resumen, la figura del Subdelegado adquiera un carácter netamente funcionarial.

* Los Subdelegados del Gobierno son órganos directivos con nivel de Subdirectores Generales, por tanto, no son considerados altos cargos de la Administración como sí ocurría con los Gobernadores Civiles. 
* Los Subdelegados son funcionarios de la Administración que pasan a la situación administrativa de servicio especial y su régimen retributivo será el establecido para los funcionarios públicos. Los Gobernadores Civiles que antes de su nombramiento eran funcionarios públicos pasaban a la excedencia.

* Los Subdelegados del Gobierno, al perder la condición de alto cargo, están sometidos al régimen retributivo previsto para los funcionarios públicos. Los Gobernadores Civiles como altos cargos de la Administración tenían derecho al sueldo y gastos de representación que en los Presupuestos Generales del Estado se asignaban a los Directores Generales, salvo alguna excepción.

* Las competencias de los Subdelegados del Gobierno no aparecen desarrolladas en el Real Decreto de abril de 1997 sino en la Ley de Organización y Funcionamiento de la Administración General del Estado, concretamente, en su artículo 29.2; mientras las de los Gobernadores Civiles sí que aparecían de forma expresa en el Estatuto de Gobernadores de 1980.

* Los Subdelegados del Gobierno se convierten en simple funcionario, de ahí, que pierdan parte de la capacidad sancionadora que ostentaba el Gobernador civil. Las competencias sancionadoras atribuidas a los Gobernadores por la Ley orgánica 1/1992, de 21 de febrero, sobre Protección de la Seguridad Ciudadana, y por la Ley 23/1992, de 30 de julio, de Seguridad Privada, no son asumidas por el Subdelegado, sino que pasan a ser ejercidas por el Delegado del Gobierno en las CC.AA. A los Subdelegados del Gobierno se les restringe las competencias en materia sancionadora y de policía. Pero, no podemos olvidar la posibilidad de que el Delegado del Gobierno puede delegar en éstos distintas competencias ${ }^{5}$.

En definitiva, los Subdelegados del Gobierno van a seguir siendo los responsables de coordinar todo el aparato de la Administración General del Estado en la provincia y, cuando proceda, también de mantener una relación armónica con el resto de niveles administrativos, pero siempre bajo la supervisión del responsable último de la Administración Central, como es el Delegado del Gobierno que es quien lo ha nombrado.

\footnotetext{
5 Ejemplo de esta delegación lo tenemos en la Resolución de 29 de abril de 1997, por la que el Delegado del Gobierno en la Comunidad Autónoma de Aragón delega ciertas competencias en favor de determinadas autoridades, entre ellas, los Subdelegados del Gobierno. En esta Resolución y en aras a los principios del art. $103 \mathrm{CE}$ y, en especial, a los de eficacia y agilidad delega en los Subdelegados competencias en materia de personal funcionario, de sanidad, de extranjería, de procesos electorales, en materia de daños a víctimas del terrorismo, en relación con la propaganda comercial aérea y en relación con los edificios administrativos de Servicios Múltiples (BOA de 2 de mayo de 1997).
} 
COMENTARIO A LA SUPRESIÓN DE LOS GOBERNADORES CIVILES ...

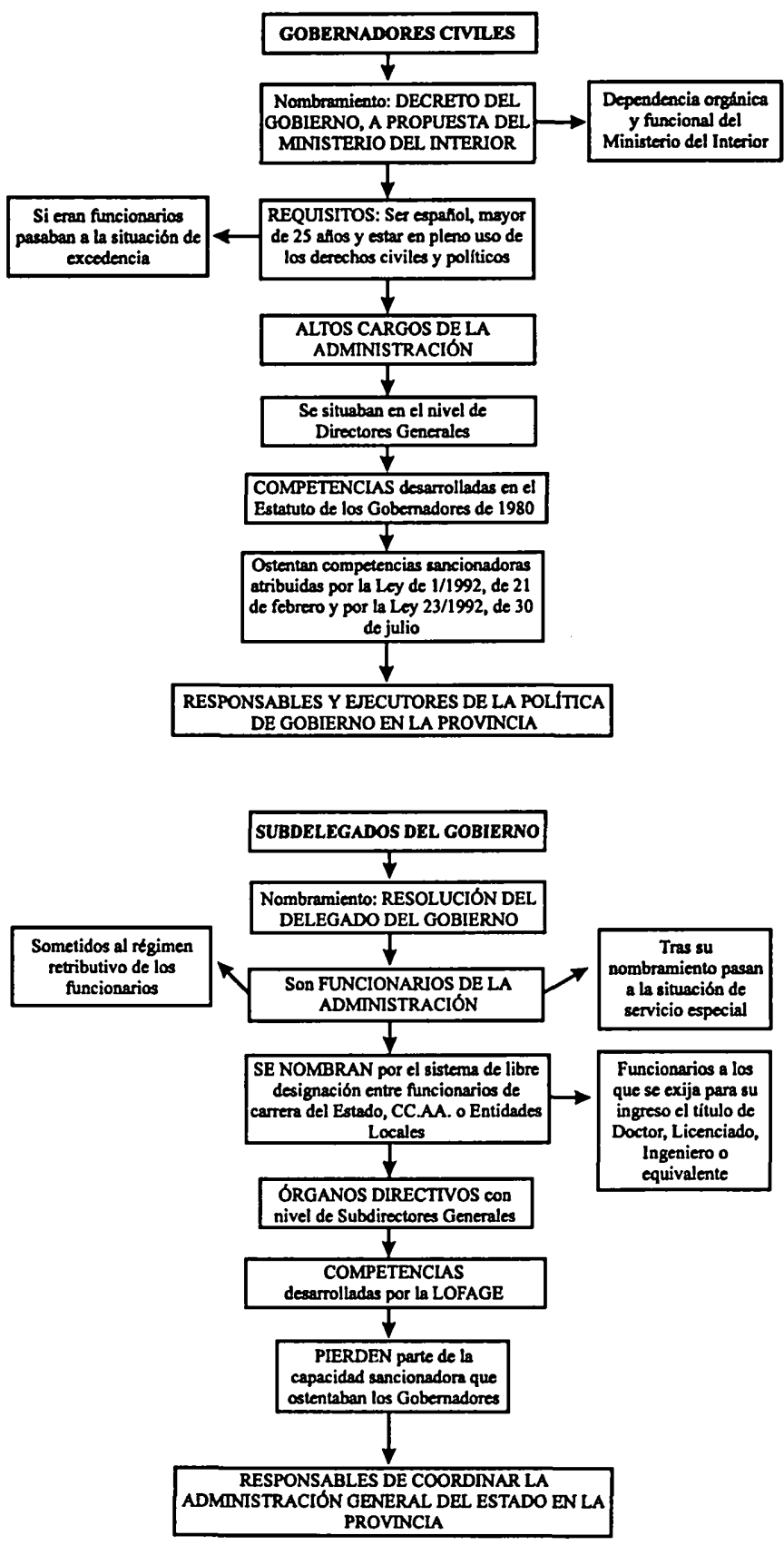

543 
REAL-1997, núm. 274-275. MELÚS GIL, ISABEL. COMENTARIO A LA SUPRESIÓN DE LOS GOB...

REAL-1997, núm. 274-275. MELÚS GIL, ISABEL. COMENTARIO A LA SUPRESIÓN DE LOS GOB... 